\title{
THE MEDIATOR ROLE OF EMOTIONAL INTELLIGENCE WHICH IS EFFECTED BY TRANSFORMATIONAL AND STRATEGIC LEADERSHIP ON ETHICAL CLIMATE
}

\author{
"Şebnem ASLAN \\ "Demet AKARÇAY \\ ** Serpil AĞCAKAYA \\ *Selçuk University, Konya, Turkey \\ ${ }^{* *}$ Suleyman Demirel University, Isparta, Turkey
}

\begin{abstract}
In this study, the mediating role of emotional intelligence in the effect of transformational leadership and strategic leadership on ethical climate was investigated. The research was executed in 4 different hospitals among 200 healthcare employees in the province of Konya, in Turkey. In the consequences of the research, strategic leadership influences the ethical climate and emotional intelligence has a mediating role in the relationship between strategic leadership and ethical climate. It is also determined that emotional intelligence has designated ethical climate. It is concluded that transformational leadership has not determined the ethical climate and emotional intelligence has no statistically significant mediating effect on the correlation between transformational leadership and ethical climate.
\end{abstract}

Keywords: Transformational Leadership, Strategic Leadership, Ethic Climate, Emotional Intelligence

\section{INTRODUCTION}

Ethical climate has located within the important points in healthcare institutions as well as the other institutions, because, in healthcare institutions, situations, called as ethical crises or ethical hazard, and some situations as presenting low quality healthcare, failed patient support, giving unrealistic hopes to patients and their relatives occur in an environment dominated a low ethical climate (Schluter, Winch, Holzhauser, \& Henderson, 2008). Within the organizations, there are some evidence that emphasize the relationship between ethical issues and the level of care quality, patient and employee outputs and therefore the development of assemblies about ethical issues and the maintenance of ethical debates is crucial in all healthcare institutions, regardless of their sizes and definitions, in order to increase ethical issues (Suhonen, Stolt, Virtanen, \& Leino-Kilpi, 2011). Ethical integrity of leaders has been defined as how to be in relationship with right and wrong behaviors in work environment in accordance with rules and standards for morality, moral principles, right behaviors and implementations (Thoms, 2008). In this sense, it is assumed that have being qualified managers, strategic and transformational leadership would allow the creation of ethical climate in organizations (Aswegen \& Engelbrecht, 2009; Brown \& Treviño, 2006; Sağnak, 2010; Engelbrecht, Aswegen, \& Theron, 2005). Accordingly, it is considered that the evaluation of healthcare employees about their executives how they are strategic and transformational, would be a determinant of ethical climate. Therefore, in this study two types of leadership as strategic and transformational, which impact on ethical climate, have been investigated. On the other hand, another variable, which effects ethical climate, is assumed as variable of emotional intelligence (Deshpande \& Joseph, 2009). As it is conceived that emotional intelligence has been defined as the awareness of both individuals and the others (Modassir \& Singh, 2008) and used in affective communication (Prati, Douglas, Ferris, Ammeter, \& Buckley, 2003), it has been assumed that it would affect the process of building ethical climate. Then, communication and perception have a great deal of importance to constitute ethical climate (Ruppel \& Harrington, 2000). For this reason, in the research the self evaluation of employees related emotional intelligence as another variable, which affects ethical climate. This effect is also assumed as mediating variable between leaderships and ethical climate. 


\section{LITERATURE REVIEW}

\section{Ethical Climate}

'Moral Culture' is an essential concept in order to apprehend ethical climate environment better. Moral culture could be defined as behaviors, which are developed by a group of executives, their employees, entrepreneurs and suppliers and have displayed the separations between their right or wrong behavior rules or principles, covered the whole organization and are transmitted intergeneration (Thoms, 2008). On the basis of all these definitions, ethical climate is identified as the general perception about the issues, which are considered as ethical in the context of an organization (Malloy, et al., 2009). In general, while organizational culture is guiding about the incidence of organizational members' behaviors, in particular ethical climate is focusing on right or wrong issues (Ferrell, Johnston, \& Ferrell, 2007). Ethical climate has observed among employees and could be seen as a mix of organizational perception of ethical values and behaviors, which are performed and supported by organizational members, because it guides for employee behaviors as a form of cultural control (Schwepker \& Hartline, 2005). The theory of ethical climate was shaped by Victor and Cullen (1987) and identified as the perception of behaviors, accepted ethically, among the employees and the approach of ethical issues (Goldman \& Tabak, 2010). Besides, important ethical issues facing healthcare managers in organizational decision making could be arrayed as competitive values that are essential for a broader service of health care and ethical experiences of healthcare leaders (Suhonen, Stolt, Virtanen, \& Leino-Kilpi, 2011). The examination of ethical climate has assisted to be understood the effects on implementations in business environment, the scope of organizational change and the effectiveness of organizational interventions (Pauly, Varcoe, Storch, \& Newton, 2009).

Healthcare institutions contain a different structure from the other organizations. To give an example, in a research, ethical conflicts, which include physicians and nurses, were identified under five topics: these are, be not supported healthcare professionals by themselves and the organization or not value for each other and connected with that feel themselves not to be committed to the organization. Due to insufficient or scarce resources, as a result of the poor quality of care, patient safety and negative consequences in terms of quality of work life and not being participated in organizational policies need to be followed the conflicts of healthcare employees with the organizational values. In addition, blinding of management could be defined as focus of executives on especially a clinical problem or a situation or have no intervention for a problem even if he/she has been aware of it. Finally, ethical conflicts have been displayed as the lack of transparency and openness within the organization (Gaudine, LeFort, Lamb, \& Thorne, 2011). Executives has explain organizational ethical climate, which includes values, norms and informal symptoms, in order to define ethical issues (Ferrell, Johnston, \& Ferrell, 2007). Ethical climate could change as a new leadership approach endures and organizational implementations refresh (Goldman \& Tabak, 2010). Therefore, this study discusses ethical leadership approaches that influence ethical climate.

\section{Transformational Leadership}

Transformational leadership approaches emerged with the discussion of 'rebellion leadership' of Dawton in 1973 and the concept was recognized by Burns, famous historian of USA, in 1978. Then, it was moved to the fields of management and organization by Bass and House (Aslan, 2009). A transformational leader could be signed as an accelerator, which converts employee motivation to commitment and this commitment into acceptable successes (Modassir \& Singh, 2008: 4). For the type of transformational leadership, leaders focus on the need for definition of the future for their followers, how they lead the followers, who would determine the goals and how would be achieved these goals (Sarwat, Hayat, Qureshi, \& Ali, 2011).

In the study, executed by Sarwat et al. (2011), it has been expressed that transformational leadership has an effect on increasing organizational performance (Sarwat, Hayat, Qureshi, \& Ali, 2011). Transformational leadership is considered as the best approach in order to be processed ethical behaviors within the organization (Carlson \& Perrewe, 1995). Transformational leadership has an association with self-sacrifice, universal rights and deontological values, which regenerate motivational and inspiring basic behaviors that mobilize effective leadership outcomes in organizations and emphasize strong believes towards principles embodied in the infrastructure (Groves \& LaRocca, 2011). In the type of transformational leadership, considering the ethical consequences of decisions and acting in conformity with moral principles in order to generate ethical 
role models for the others could have significance (Brown \& Treviño, 2006). In the process of transformational leadership, the leader has attempted to conduct the believes and values of his/her followers into a change so as to achieve the organizational goals (Grundstein-Amado, 1999). For this reason, transformational leadership is envisaged as the most important affecting factor for ethical climate in our study. It is believed that transformational leaders have positive impacts on ethical performance of the organizations (Carlson \& Perrewe, 1995). Sağnak's (2010) study has showed that there is a positive correlation between all dimensions of transformational leadership and all types of ethical climate and this result was interpreted as transformational leadership is one of the key determinants of ethical climate (Sağnak, 2010).According to the results of the study, conducted by Engelbrecht et al. (2005), it is determined that transformational leadership has an positive influence on ethical climate (Engelbrecht, Aswegen, \& Theron, 2005). Based on the results of this study, this study investigates the relation between transformational leadership and ethical climate. In line with this aim, hypothesis 1 is developed. H1: Transformational leadership is positively related to ethical climate.

\section{Strategic Leadership}

In strategic leadership, which has been defined by Ireland and Mitt (1999) as a person's ability of prior predictions, prefiguration, maintaining flexibility, strategic thinking and the ability of teamwork with the aim of being started the changes to create a viable future (Kjelin, 2009). In view of Worden (2003), strategic leadership has been defined as related view of macro environmental system on organization that differentiated ideologies, identity, mission and basic skills of an organization (Akbar \& Zaman, 1993). Strategic leaders affect the organizations by enhancing the learning capacity of their organizations in accordance with Boal and Hooijberg (2000) (Phipps \& Burbach, 2010; Boal \& Hooijberg, 2000). Strategic leadership has been separated from other categories of leadership by use of two basic points, on account of not being a new category of leadership. These are 1) what the strategic leaders are doing, 2) exhibit characteristics of strategic leaders and 3) a developed model for strategic leadership (Davies \& Davies, 2006). In other words, strategic leadership has appeared as creating links within the organization and also among the organizations (Kjelin, 2009). Davies (2003) has basically stressed that a strategic leader has been able to see the future, make organizational arrangement by taking into consideration the big picture, need a roadmap for the future situations and has an ability to identify criteria for strategic changes within the organization (Davies, 2003). Strategic leaders at the same time have discovered long-term agenda of strategic plans for their own and the other related institutions in the sector and as well as for community, political leaders, consumer groups (Boal \& Hooijberg, 2000). Strategic leadership has to focus on knowledge and personality of decision-makers (Akbar \& Zaman, 1993). The responsibilities of strategic leadership for executives have to contain creating goals and maintenance of ethical climate in that employees behave as a routine work ethically in order to begin changes (Thomas \& Dienhart, 2004). Thus, in line with this aim, it is expected that strategic leader behave in positively constructive role in ethical climate and Hypothesis 2 is developed. H2: Strategic leadership is positively related to ethical climate. Emotional intelligence is assumed as a factor, which has a mediation role in the effect of ethical climate and involves perceptions of employees. For this reason, the concept of emotional intelligence is added in the research in the third dimension.

\section{Emotional Intelligence}

'Emotional Intelligence' has expressed as an area of intelligence and gained popularity as a concept that oriented monitoring of experiences with the published book by Goleman (1995) (Schutte, et al., 1998). Emotional intelligence refers to ability of represent the causes and solutions of problems based on emotions in order to identify feelings, meanings and relationships (Mayer, Caruso, \& Salovey, 2000). Firstly, the concept of 'emotional intelligence' was used by Salovey and Mayer (1990) and is considered as a from of three categories that consisted of adaptive skills. These could be classified as evaluation and expression of emotions, regulation of emotions and using of emotions in problem solving (Schutte, et al., 1998). In the literature, there are encountered studies examining the relationships with management, ethics and emotional intelligence with the respect of this research subject (Holian, 2006). The researches concerning emotions in workplace have been interested in ethical dilemmas due to different emotions and have affected employees' character, emotions and also emotions have influence decision making (Zerbe, 2008). Based on the results of these studies, this study investigates the relation between emotional intelligence and ethical climate. In line with this aim, hypothesis 3 is developed. H3: Emotional intelligence is positively related to ethical climate. 
In the study executed by Fatima et al. (2010), it has been expressed that emotional intelligence has a positive and significant impact on transformational leadership (Fatima, Imran, \& Zaheer, 2010). Strategic leaders have assumed roles with information equipment skills and abilities such as developing changes and achieving goals, indicating awarding possibilities for the other to be creative, determining goals, sharing information and receiving feedback, because they have responsibilities arise from strategic decisions for their organizations and in this regard it is emphasized the importance of being strategic leadership with emotional intelligence (Coco, 2011). In addition, it is assume that being able to influence of both types of leaderships on ethical climate would be dependent on awareness of both employees and also the others and could be related with the using that in their relations effectively. It is expressed like in the attribution theory that leadership has occurred as association with the employees' evaluation of their executives. On the other hand, ethical climate depend on the full participation of the employees, as for that full participation would be no doubt related to awareness. Finally, it was considered that emotional intelligence will have a mediating effect on transformational and strategic leadership of ethical climate and hypotheses $4 \mathrm{a}$ and $4 \mathrm{~b}$ were developed. H4a: Emotional intelligence has a mediating role on the relation between transformational leadership and ethical climate. H4b: Emotional intelligence has a mediating role on the relation between strategic leadership and ethical climate.

\section{METODOLOGY}

\section{Research Goal}

In this study, it was investigated that the role of mediator emotional intelligence which is effected by transformational and strategic leadership on ethical climate.

\section{Sample and Data Collection}

The study includes five hospitals in Konya province of Turkey. The sample mostly consists of male $(59 \%)$ and $34 \%$ are collage graduate. Average age of the participants is 31.08 . In this research, the data were evaluated by the packaged software of SPSS 10.0. To examine the content validity of the measures, was tested by confirmatory factor analysis (CFA) and path analysis was performed by LISREL VIII program using a sample of 200 healthcare employees in hospitals in Konya, province of Turkey.

\section{Analyses and Results}

In the study, the measures of transformational leadership, strategic leadership, emotional intelligence and ethical climate were used. More detailed information is given about the scales below. The Ethical Climate Questionnaire Scale: The scale was developed by Victor and Cullen (1988), used by Weber (1995) and has been identified as valid and reliable scale. Scale has consisted of five dimensions as "Caring Climate", "Law and Code Climate", "Rules Climate", "Instrumental Climate" and "Independence Climate" and it is rated with 6 - point likert ( $1=$ totally wrong, $6=$ totally right). Caring climate has consisted of 7 questions; law and code climate 4 questions; rules climate 4 questions; instrumental climate 7 questions; independence climate 4 questions. Multifactor Leadership Scale: It is a 4- dimensions scale, which has been obtained from the study of Kanste, Miettunen and Kyngas (2007). Scale dimensions have consisted of total 15 questions as "idealized influence", 4 questions; "inspirational motivation", 3 questions; "intellectual stimulation", 4 questions; and "individualized consideration" 4 questions. Scale is rated with 5 - point likert ( $1=$ Not at all, $6=$ Frequently, if not always). Strategic Leadership Scale: This scale has been obtained from the study of Pisapia, ReyesGuerra, Coukos-Semmel (2005) and has consisted of "reflecting", 15 questions; reframing, 10 questions; system thought, 13 questions. Scale is rated with 5- point likert ( $1=$ not important, 5= very important). Emotional Intelligence Scale: It has been obtained from the study of Chan (2004) and has 4 dimensions like as, "empathic sensitivity", "positive regulation", positive utilisation" and " emotional appraisal". Each dimension has been consisted of 3 questions. Scale is rated with 5- point likert $(1=$ never, $5=$ always $)$.In order to examine the content validity of those measures, we performed confirmatory factor analysis (CFA) with LISREL VIII (Joreskog \& Sorbom, 1996) using a sample of 200 healthcare employees for hospitals in Konya province of Turkey. 
Table 1.1. Items and item loadings from confirmatory factor analyses

\begin{tabular}{|c|c|c|c|c|c|c|}
\hline Items & (CFA) & $\begin{array}{c}t- \\
\text { Value }\end{array}$ & $\begin{array}{c}\text { Cronbach } \\
\text { Alpha } \\
\text { Item }\end{array}$ & Mean & SS & $\begin{array}{c}\text { Item-Total } \\
\text { Correlations }\end{array}$ \\
\hline Strategic Leadership & & & .8897 & & & \\
\hline Reflecting & & & .7167 & & & \\
\hline s2 & .64 & 9.11 & & 3.76 & .94 & .782 \\
\hline s13 & .70 & 10.09 & & 3.67 & .95 & .805 \\
\hline s15 & .69 & 10.04 & & 3.62 & .93 & .810 \\
\hline Reframing & & & .7332 & & & \\
\hline s16 & .78 & 11.82 & & 3.51 & .97 & .809 \\
\hline s22 & .59 & 8.39 & & 3.55 & 1.01 & .801 \\
\hline s23 & .68 & 9.99 & & 3.36 & 1.02 & .814 \\
\hline System Thought & & & .8489 & & & \\
\hline $\mathrm{s} 32$ & .70 & 10.80 & & 3.46 & .98 & .780 \\
\hline s33 & .74 & 11.44 & & 3.33 & 1.05 & .807 \\
\hline s34 & .75 & 11.88 & & 3.47 & 1.07 & .788 \\
\hline s36 & .74 & 11.64 & & 3.31 & 1.08 & .810 \\
\hline s38 & .69 & 10.47 & & 3.49 & 1.05 & .763 \\
\hline
\end{tabular}

Note: Standardized item loadings reported for CFA. $p<.001$ for all loadings. **Correlation is significant at the 0.01 level (2tailed).

Confirmatory factor analysis was applied to the initial version of Strategic Leadership scale and threefactor structure has been reached. Factor loads relating to each factor are given in Table 1. After that, the goodness of fit of this scale was investigated. The goodness-of-fit measures were used to assess the overall model fit. Goodness-of-Fit Statistics: $\chi 2 / \mathrm{df}=48.97 / 41=1.19, \mathrm{NNFI}=.98, \mathrm{CFI}=.99$, AGFI $=.93, \mathrm{GFI}=.96, \mathrm{IFI}=.99$, RMSEA $=.03$. Acceptable reliability limit for .50 according to correction indexes 12 questions from dimension of Reflecting; 7 questions from Reframing; 8 questions from System Thought were moved from the scale because factor loads of each questions should be above .70. Accordingly, the goodness of fit of the scale has been found as acceptable. The reliability of the scale was tested with Cronbach Alpha Reliability Co efficiency. The values were found between .72.89 and named as reliable. At the end of the application, means and Standard deviation of the items were showed in Table 1. Mean values have been observed as high. Total-item correlations of factors were examined for level of internal consistency for scale. Item-total correlation was examined for the relationship of each items with overall scale score. The item-total correlations for the scale of Strategic Leadership items were: the values that have changed between .76- .81, were obtained. Accordingly, it could be expressed that strategic leadership scale has been showing a good level of internal consistency for the scale.

Confirmatory factor analysis was applied to the initial version of Strategic Leadership scale and fivefactor structure has been reached. Factor loads relating to each factor are given in Table 1. Acceptable reliability limit for .50 according to correction indexes 4 questions from dimension of caring climate; 1 question from law and code climate; 1 question from rules climate; 4 questions from instrumental climate; 1 question from independence climate were moved from the scale because factor loads of each questions should be above .70. After that, the goodness of fit of this scale was investigated. The goodness-of-fit measures were used to assess the overall model fit. Goodness-of-Fit Statistics: $\chi 2 / \mathrm{df}$ $=157.93 / 80=1.97, \mathrm{NNFI}=.92, \mathrm{CFI}=.94, \mathrm{AGFI}=.86, \mathrm{GFI}=.90, \mathrm{IFI}=.94, \mathrm{RMSEA}=.07$. Accordingly, the goodness of fit of the scale have been found as acceptable. The values were found between $.80-.85$ and named as reliable. At the end of the application, means and Standard deviation of the items were showed in Table 1. Mean values have been observed as high. Total-item correlations of factors were 
examined for level of internal consistency for scale. Item-total correlation was examined for the relationship of each items with overall scale score. The item-total correlations for scale of ethical climate items were: the values that have changed between .83- .89 , were obtained. Accordingly, it could be expressed that ethical climate scale has been showing a good level of internal consistency for the scale.

Table 1.2. Items and item loadings from confirmatory factor analyses

\begin{tabular}{|c|c|c|c|c|c|c|}
\hline Items & (CFA) & $\begin{array}{c}t- \\
\text { Value }\end{array}$ & $\begin{array}{c}\text { Cronbach } \\
\text { Alpha } \\
\text { Item }\end{array}$ & Mean & SS & $\begin{array}{c}\text { Item-Total } \\
\text { Correlations }\end{array}$ \\
\hline The Ethical Climate ${ }^{(2)}$ & & & .8892 & & & \\
\hline Caring Climate & & & .8010 & & & \\
\hline S5 & .70 & 10.67 & & 4.44 & 1.34 & .847 \\
\hline S6 & .74 & 11.30 & & 4.23 & 1.21 & .833 \\
\hline S7 & .83 & 13.41 & & 4.39 & 1.19 & .857 \\
\hline Law and Code & & & .8257 & & & \\
\hline S8 & .82 & 13.42 & & 4.55 & 1.19 & .850 \\
\hline S9 & .77 & 12.30 & & 4.23 & 1.29 & .873 \\
\hline $\mathrm{S} 10$ & .77 & 12.29 & & 4.30 & 1.36 & .860 \\
\hline Rules Climate & & & .8213 & & & \\
\hline $\mathrm{S} 12$ & .82 & 13.01 & & 4.50 & 1.17 & .865 \\
\hline $\mathrm{S} 13$ & .82 & 12.93 & & 4.43 & 1.22 & .865 \\
\hline S14 & .69 & 10.27 & & 4.09 & 1.30 & .844 \\
\hline Instrumental Climate & & & .8063 & & & \\
\hline S19 & .70 & 10.50 & & 4.00 & 1.36 & .833 \\
\hline S20 & .89 & 14.24 & & 3.63 & 1.27 & .878 \\
\hline S21 & .73 & 11.16 & & 3.64 & 1.28 & .838 \\
\hline Independence Climate & & & .8514 & & & \\
\hline S24 & .77 & 12.11 & & 3.86 & 1.27 & .866 \\
\hline S25 & .87 & 14.20 & & 3.72 & 1.33 & .898 \\
\hline S26 & .76 & 11.85 & & 3.90 & 1.34 & .871 \\
\hline
\end{tabular}

Note: Standardized item loadings reported for CFA. $p<.001$ for all loadings. **Correlation is significant at the 0.01 level ( 2 tailed).

Confirmatory factor analysis was applied to the initial version of emotional intelligence scale and fivefactor structure has been reached. Factor loads relating to each factor are given in Table 1. After that, the googness of fit of this scale was investigated. The goodness-of-fit measures were used to assess the overall model fit. Goodness-of-Fit Statistics: $\chi 2 / \mathrm{df}=103.70 / 48=2.16$, NNFI=.93, CFI=.95, $\mathrm{AGFI}=.87, \mathrm{GFI}=.92, \mathrm{IFI}=.95$, RMSEA $=.07$. Accordingly, the goodness of fit of the scale have been found as acceptable. The reliability of the scale was tested with Cronbach Alpha Reliability Co efficiency. The values were found between .78-.90 and named as reliable. At the end of the application, means and Standard deviation of the items were showed in Table 1. Mean values have been observed as high. Total-item correlations of factors were examined for level of internal consistency for scale. Item-total correlation was examined for the relationship of each item with overall scale score. The item-total correlations for scale of emotional intelligence items were: the values that have changed between .81- .88, were obtained. Accordingly, it could be expressed that emotional intelligence scale has been showing a good level of internal consistency for the scale. 
Table 2. Items and item loadings from confirmatory factor analyses

\begin{tabular}{|c|c|c|c|c|c|c|}
\hline Items & (CFA) & $t$-Value & $\begin{array}{c}\text { Cronbach } \\
\text { Alpha } \\
\text { Item }\end{array}$ & Mean & SS & $\begin{array}{l}\text { Item-Total } \\
\text { Correlations }\end{array}$ \\
\hline Emotional & & & .9008 & & & \\
\hline Empathic & & & .8244 & & & \\
\hline $\mathrm{S} 1$ & .83 & 13.21 & & 3.97 & .89 & .880 \\
\hline $\mathrm{S} 2$ & .79 & 12.39 & & 3.92 & .85 & .857 \\
\hline S3 & .78 & 12.13 & & 3.99 & .82 & .843 \\
\hline Positive Regulation & & & .7843 & & & \\
\hline S4 & .68 & 10.17 & & 3.96 & .98 & .804 \\
\hline S5 & .78 & 12.03 & & 3.92 & 1.03 & .863 \\
\hline S6 & .77 & 11.92 & & 3.64 & 1.01 & .839 \\
\hline Positive Utilisation & & & .8016 & & & \\
\hline S7 & .88 & 14.91 & & 4.07 & .85 & .863 \\
\hline S8 & .81 & 13.12 & & 4.13 & .88 & .873 \\
\hline S9 & .65 & 9.79 & & 3.90 & .93 & .808 \\
\hline Emotional & & & .8011 & & & \\
\hline S10 & .83 & 13.55 & & 3.90 & .92 & .859 \\
\hline S11 & .77 & 12.17 & & 3.99 & .85 & .869 \\
\hline $\mathrm{S} 12$ & .71 & 10.76 & & 3.94 & .94 & .814 \\
\hline Multifactor & & & .9501 & & & \\
\hline Idealized Influence & & & .8556 & & & \\
\hline $\mathrm{S} 1$ & .75 & 12.05 & & 2.62 & 1.24 & .820 \\
\hline S2 & .79 & 12.92 & & 2.83 & 1.24 & .838 \\
\hline S3 & .83 & 13.93 & & 2.98 & 1.23 & .882 \\
\hline S4 & .70 & 10.98 & & 3.24 & 1.20 & .801 \\
\hline Inspirational & & & .8162 & & & \\
\hline S5 & .78 & 12.82 & & 3.06 & 1.22 & .859 \\
\hline S6 & .80 & 13.42 & & 3.00 & 1.22 & .877 \\
\hline S7 & .72 & 11.61 & & 3.14 & 1.22 & .830 \\
\hline Intellectual & & & .8799 & & & \\
\hline S8 & .92 & 16.78 & & 3.01 & 1.26 & .921 \\
\hline S9 & .89 & 15.79 & & 2.98 & 1.24 & .916 \\
\hline S10 & .73 & 11.77 & & 2.64 & 1.22 & .855 \\
\hline Individualized & & & .8157 & & & \\
\hline S12 & .77 & 12.50 & & 3.22 & 1.24 & .858 \\
\hline S13 & .74 & 11.75 & & 3.02 & 1.22 & .838 \\
\hline $\mathrm{S} 15$ & .78 & 13.67 & & 3.12 & 1.26 & .868 \\
\hline
\end{tabular}

Note: Standardized item loadings reported for CFA. $p<.001$ for all loadings. **Correlation is significant at the 0.01 level (2tailed).

Confirmatory factor analysis was applied to the initial version of emotional intelligence scale and four-factor structure has been reached. Factor loads relating to each factor are given in Table 1. Acceptable reliability limit for .50 according to correction indexes 1 question from dimension of intellectual stimulation and 1 question from individualized consideration were moved from the scale because factor loads of each questions should be above .70. After that, the goodness of fit of this scale was investigated. The goodness-of-fit measures were used to assess the overall model fit. Goodnessof-Fit Statistics: $\chi 2 / \mathrm{df}=115.49 / 59=1.95, \quad \mathrm{NNFI}=.95, \mathrm{CFI}=.98, \quad \mathrm{AGFI}=.87, \mathrm{GFI}=.92, \mathrm{IFI}=.98$, 
RMSEA $=.06$. Accordingly, the goodness of fit of the scale has been found as acceptable. The values were found between .81-.95 and named as reliable. At the end of the application, means and Standard deviation of the items were showed in Table 1. Mean values have been observed as high. Total-item correlations of factors were examined for level of internal consistency for scale. Item-total correlation was examined for the relationship of each items with overall scale score. The item-total correlations for scale of transformational leadership items were: the values that have changed between .80- .92, were obtained. Accordingly, it could be expressed that transformational leadership scale has been showing a good level of internal consistency for the scale.

It is determined whether the relationship between transformational leadership and ethical climate by using path analysis. As a result of path analysis, path coefficient between transformational leadership and ethical climate $.21(\mathrm{p}<.01)$ was found statistically significant. As goodness of fit indexes were examined on the model 1; the values were determined that CFI (Comparative fit index) as .91, GFI (Goodness of fit index) as .88, AGFI (Adjusted goodness of fit index) as . 83, $\chi 2$ (chi square) as 225.06, degree of freedom (df) $=100$, the value of $\chi 2 / \mathrm{df}$ as 2.25 and RMSEA (Root mean square error of approximation) as 0.07 . It could not be said as the model is acceptable, then the values obtained in the model are below the acceptable values $(0,95 \leq \mathrm{CFI} \leq 0,97 ; 0,90 \leq \mathrm{GFI} \leq 0,95 ; 0,85 \leq \mathrm{AGFI} \leq 0,90)$ (Schermelleh and Moosbrugger, 2003). Accordingly, path analysis between transformational leadership and ethical climate could not show goodness of fit. The Hypothesis 1 is rejected.

The relationship between strategic leadership and ethical climate was determined by using path analysis. As a result of path analysis, path coefficient between strategic leadership and ethical climate $.63(\mathrm{p}<.01)$ was found statistically significant. As goodness of fit indexes were examined on the model 2; the values were determined that CFI (Comparative fit index) as .95, GFI (Goodness of fit index) as .90 , AGFI (Adjusted goodness of fit index) as . 88, $\chi 2$ (chi square) as 186.81, degree of freedom $(\mathrm{df})=100$, the value of $\chi 2 / \mathrm{df}$ as 1.86 and RMSEA (Root mean square error of approximation) as 0.06 . It could be said as the model is acceptable, then the values obtained in the model are in the acceptable values $(0,95 \leq \mathrm{CFI} \leq 0,97 ; 0,90 \leq \mathrm{GFI} \leq 0,95 ; 0,85 \leq \mathrm{AGFI} \leq 0,90)$. Accordingly, path analysis between strategic leadership and ethical climate has showed goodness of fit. The Hypothesis 2 is accepted.

The relationship between emotional intelligence and ethical climate was determined by using path analysis. As a result of path analysis, path coefficient between emotional intelligence and ethical climate $.58(\mathrm{p}<.01)$ was found statistically significant. As goodness of fit indexes were examined on the model 3; the values were determined that CFI (Comparative fit index) as .94, GFI (Goodness of fit index) as .90, AGFI (Adjusted goodness of fit index) as . 85, $\chi 2$ (chi square) as 196.72, degree of freedom $(\mathrm{df})=100$, the value of $\chi^{2} / \mathrm{df}$ as 1.96 and RMSEA (Root mean square error of approximation) as 0.07 . It could be said as the model is acceptable, then the values obtained in the model are in the acceptable values $(0,95 \leq \mathrm{CFI} \leq 0,97 ; 0,90 \leq \mathrm{GFI} \leq 0,95 ; 0,85 \leq \mathrm{AGFI} \leq 0,90)$. Accordingly, path analysis between emotional intelligence and ethical climate have showed goodness of fit. The Hypothesis 3 is accepted.

The data was analyzed within the scope of mediating variables conditions in order to designate mediation role of emotional intelligence in the relationship between transformational leadership and ethical climate. The relationship between emotional intelligence and ethical climate was determined by using path analysis. As a result of path analysis, it is settled that there is no significant relation between transformational leadership and ethical climate due to low model goodness (Figure 1). As emotional intelligence, which is mediating variable, was participated in the model, as a result of the analysis it is seen the correlations significantly between transformational leadership and emotional intelligence $(.17, \mathrm{p}<.01)$, emotional intelligence and ethical climate $(.52, \mathrm{p}<.01)$. But as goodness of fit indexes were examined on the model 4; the values were determined that CFI (Comparative fit index) as .92, GFI (Goodness of fit index) as .88, AGFI (Adjusted goodness of fit index) as . 84, $\chi 2$ (chi square) as 217.47 , degree of freedom (df) $=100$, the value of $\chi^{2} / \mathrm{df}$ as 2.17 and RMSEA (Root mean square error of approximation) as 0.07 . It could not be said as the model is acceptable, then the values obtained in the model are below the acceptable values $(0,95 \leq \mathrm{CFI} \leq 0,97 ; 0,90 \leq \mathrm{GFI} \leq 0,95$; $0,85 \leq \mathrm{AGFI} \leq 0,90)$. Accordingly, emotional intelligence has no mediating role between transformational leadership and ethical climate. Hypothesis 4a is rejected.

The data was analyzed within the scope of mediating variables conditions in order to designate mediation role of emotional intelligence in the relationship between strategic leadership and ethical climate. The relationship between strategic leadership and ethical climate was determined by using path analysis. As a result of path analysis, path coefficient between strategic leadership and ethical 
climate $.63(\mathrm{p}<.01)$ was found statistically significant. As emotional intelligence, which is mediating variable, was participated in the model, as a result of the analysis it is seen the relations significantly between strategic leadership and emotional intelligence $(.48, \mathrm{p}<.01)$, emotional intelligence and ethical climate $(.33, \mathrm{p}<.01)$. As goodness of fit indexes were examined on the model $4 \mathrm{~b}$; the values were determined that CFI (Comparative fit index) as .96, GFI (Goodness of fit index) as .90, AGFI (Adjusted goodness of fit index) as . 87, $\chi^{2}$ (chi square) as 173.42, degree of freedom $(\mathrm{df})=100$, the value of $\chi 2 / \mathrm{df}$ as 1.73 and RMSEA (Root mean square error of approximation) as 0.06 . It could be said as the model is acceptable, then the values obtained in the model are in the acceptable values $(0,95 \leq \mathrm{CFI} \leq 0,97 ; 0,90 \leq \mathrm{GFI} \leq 0,95 ; 0,85 \leq \mathrm{AGFI} \leq 0,90)$. In the last part, it is studied to determine whether emotional intelligence is a partial or full mediating variable. In this stage, according to the mediating variable' conditions, no correlation between strategic leadership and ethical climate has indicated full mediation, if there is a relationship decreasing coefficient of this relationship has indicated partial mediation. In this model, the path coefficient between strategic leadership and ethical climate was .63 $(\mathrm{p}<.01)$, but then it decreased $(.44, \mathrm{p}<.01)$. Accordingly, emotional intelligence has a mediating role between strategic leadership and ethical climate. Hypothesis $4 \mathrm{~b}$ is accepted.

\section{CONCLUSION}

In this research, the mediating role of emotional intelligence on the effect of transformational leadership and strategic leadership on ethical climate has been investigated. In consequence of the study, these results were achieved that strategic leadership has influenced ethical climate and emotional intelligence has a mediating role in the relationship between strategic leadership and ethical climate. It is also designated that emotional intelligence has affected ethical climate. It has been concluded that transformational leadership has not determined the ethical climate and emotional intelligence has also no statistically significant correlation between transformational leadership and ethical climate. In this study, emotional intelligence has a positive correlation with ethical climate (Deshpande \& Joseph, 2009) and strategic leadership (Voola, Carlson, \& West, 2004) as expected. High emotional awareness of the employees and using this in effective communication is a process that would contribute to the constitution of ethical climate. Similarly, having emotional awareness would also strengthen strategic leadership perception of the executives. It has been expressed in the study of Leitwood et al. (2004) that emotional intelligence has an positive effect on development of executives and employees, contribution to their capabilities and making decisions for the enhancement of organizational opportunities (Leitwood et al., 2004). Another significant result in research is that strategic leadership has determined ethical climate. Basically, a crucial result has been reached, because employees, who think their executives as leaders, have been observed with positive view in terms of ethical climate. For this reason, the presence of strategic leadership is inevitable in the determinant of ethical culture and ethical climate. Thus, in the studies executed in the area of strategic leadership, this type of leadership has contribution in the point of creation of ethical climate environment and systems of values (Grojean et al., 2004). In the research, it was expected that transformational leadership would affect ethical climate, but this result could not be reached. The reason of being not able to reach this result could be expressed as sluggishness of public bureaucracy. Therefore, if the hospitals were selected from private sector, it could be possible to observe leadership evaluation at stake. Our study has been separated from the literature in this sense. Transformational leaders must be in conjunction with moral virtues such as personal integrity, honesty, courage, justice and fairness and make moral decisions. At this point, it could be mentioned that the relationship between the construction process of ethical climate within the organization, ethical codes and transformational leadership (Amado, 1999). Limitation of the study is obtained by having no hospitals from private sector. Characteristics and contributions of the executives to this process could be seen as an additional point for the future researches. 


\section{REFERENCES}

Amado, R. G. (1999). Bilateral Transformational Leadership: An Appraoach For Fostering Ethical Conduct in Public Service Organizations. Administration \& Society, 31 (2), 247-260.

Aslan Ş, Duygusal Zekâ ve Dönüşümcü-Etkileşimci Liderlik, Nobel Yayınevi, Ankara, Nisan, 2009.

Chan, David W., Perceived emotional intelligence and self-efficacy among Chinese secondary school teachers in Hong Kong, Personality and Individual Differences 36 (2004) 1781-1795, s.1787

Deshpande, S. P., \& Joseph, J. (2009). Impact of Emotional Intelligence, Ethical Climate, and Behavior of Peers on Ethical Behavior of Nurses. Journal of Business Ethics 85, 403-410.

Ferrell, O., Johnston, M. W., \& Ferrell, L. (2007). A Framework for Personal Selling and Sales Management Ethical Decision Making. Journal of Personal Selling \& Sales Management, 27 (4), 291299.

Gaudine, A., LeFort, S. M., Lamb, M., \& Thorne, L. (2011). Ethical Conflicts with Hospitals: The Perspective of Nurses and Physicians. Nursing Ethics, 18 (6), 756-766.

Goldman, A., \& Tabak, N. (2010). Perception of ethical climate and its relationship to nurses' demographic characteristics and job satisfaction. Nursing Ethics, 17 (2), 233-246.

Grojean, M.W., Resick C. J., Dickson M. W., Smith, D. B. (2004). Leaders, Values, and Organizational Climate: Examining Leadership Strategies for Establishing an Organizational Climate Regarding Ethics. Journal of Business Ethics (55), 223-241.

Groves, K. S., \& LaRocca, M. A. (2011). An Empirical Study of Leader Ethical Values, Transformational and Transactional Leadership, and Follower Attitudes Toward Corporate Social Responsibility. Journal of Business Ethics, 103, 511-528.

Holian, Rosalie, (2006), "Management decision making, ethical issues and "emotional" intelligence", Management Decision, 44, 8, 1122-1138.

Kanste, Outi, Miettunen, Jouko \& Kyngas, Helvi, (2007) Psychometric properties ofthe Multifactor Leadership Questionnaire among nurses. Journal of Advanced Nursing 57(2), 201-212.

Leithwood, K., Jantzi, D., Earl, L., Watson, N., Levin, B., \& Fullan, M. (2004). Strategic Leadership for Large-Scale Reform: the Case of England's National Literacy and Numeracy Strategy. School Leadership \& Management, 24 (1), 57-79.

Malloy, D. C., Hadjistavropoulos, T., McCarthy, E. F., Evans, R. J., Zakus, D. H., Park, I., et al. (2009). Culture and Organizational Climate: nurses' insights into their relationship with physicians. Nursing Ethics, 16 (6), 719-733.

Mize, K. J., Stanforth, N., \& Johnson, C. (2000). Perceptions of Retail Supervisors' Ethical Behavior and Front-line Managers' Organizational Commitment. Clothing and Textiles Research Journal, 18 (2), 100110.

Modassir, A., \& Singh, T. (2008). Relationship of Emotional Intelligence with Transformational Leadership and Organizational Citizenship Behavior. International Journal of Leadership Studies, 4 (1), 3-21.

Pauly, B., Varcoe, C., Storch, J., \& Newton, L. (2009). Registered Nurses' Perceptions of Moral Distress and Ethical Climate. Nursing Ethics, 16 (5), 561-573.

Pisapia, John, Reyes-Guerra, Daniel and Coukos-Semmel, Deleni, (2005), Developing the Leader's Strategic Mindset: Establishing The Measures," Kravis Leadership Institute, leadership Review, Spring, Vol: 5, pp. 41-68.

Schluter, J., Winch, S., Holzhauser, K., \& Henderson, A. (2008). Nurses' Moral Sensitivity and Hospital Ethical Climate: A Literature Review. Nursing Ethics, 15 (3), 304-321.

Schermelleh, Engel, K., Moosbrugger, H. (2003). Evaluating The Fit Of Structural Equa-Equa $\neg$ tion Models: Tests Of Significance And Descriptive Goodness-Of-Fit Measures. Methods Of Psychological Research Online, 8 (2), 23-74.

Schwepker, C. H., \& Hartline, M. D. (2005). Managing the Ethical Climate of Customer-Contact Service Employees. Journal of Service Research, 7 (4), 377-397. 
Suhonen, R., Stolt, M., Virtanen, H., \& Leino-Kilpi, H. (2011). Organizational Ethics: A Literature Review. Nursing Ethics, 18 (3), 285-303.

Şimşek, O. F. 2007. Yapısal esitlik modellemesine giris temel ilkeler ve LISREL uygulamaları. Ankara: Ekinoks Publisher.

Thoms, J. C. (2008). Ethical Integrity in Leadership and Organizational Moral Culture. Leadership, 4 (4), 419-442.

Victor, B. and J. B. Cullen (1988), The Organizational Basis of Ethical Work Climates, Administrative Science Quarterly, 33, 1, 101-125.

Voola, R., Carlson, J., \& West, A. (2004). Emotional Intelligence and Competitive Advantage:Examining the Relationship From a Resource-Based View. Strategic Change, 13, 83-93.

Weber, James (1995), Influences Upon Organizational Ethical Subclimates: A Multi-Departmental Analysis of A Single Firm, Organization Science, vol: 6, no: 5, 509-523.

Zerbe, Wilfred J. 2008, "Feelings about ethical decisions: the emotions of moral residue", Research on Emotion in Organizations, 4, 109-129. 